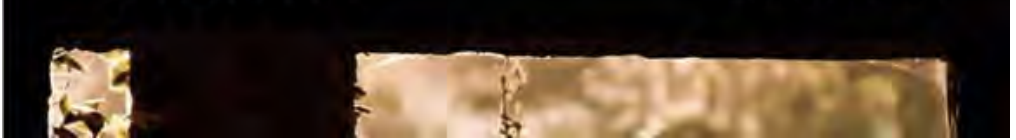

\title{
DO MANGÁ AO COSPLAY: PROCESSOS CRIATIVOS E PERFORMÁTICOS NO ENSINO DAS ARTES
}

\author{
FROM MANGA TO COSPLAY: CREATIVE AND \\ PERFORMATIC PROCESSES IN ART EDUCATION
}

DOI: http://dx.doi.org/105965198431781212016097

Jamile Brandão Neves Nemerski - Unochapecó

\begin{abstract}
RESUMO
A partir de experiências obtidas na disciplina de Estágio, componente obrigatório do curso de licenciatura em Artes Visuais, na Universidade Comunitária da Região de Chapecó Unochapecó, e da noção da popularidade do Mangá e do Cosplay junto à juventude brasileira, desenvolveu-se uma temática de ensino de Artes destinada a estudantes de todos os níveis de ensino, usando os dois elementos acima mencionados. A combinação da deslumbrante arte visual do Mangá e a natureza divertida da performace do Cosplay provaram ser eficazes no engajamento de alunos em suas respectivas aulas de Educação Artística. Porém, devido à natureza visual da temática em questão, a eficácia do método fora comprometida, uma vez que aplicada à deficientes visuais que não tinham fácil acesso a esse veio artístico, assim deixando-os, de certa forma, com um indesejável sentimento de exclusão. Visando a diversidade do programa, surgiu a ideia da reversão do processo, usando o ensino de artes no engajamento de deficientes visuais de todas as idades na cultura do Mangá e Cosplay. Essas duas situações foram pensadas e analisadas conforme as observações e as ações docentes resultantes deste estágio, realizadas nas escolas CEIM Criança é Esperança, EEB Prof ${ }^{a}$ Zélia Scharf e na Associação de Deficientes Visuais do Oeste de Santa Catarina. Resultante a isto, definiu-se dois eixos a serem analisados: O Mangá e o Cosplay como incentivo para as artes, e as Artes como incentivo para inclusão de diversas temáticas para pessoa com deficiência visual.
\end{abstract}

PALAVRAS-CHAVE: mangá, cosplay, arte, ensino, inclusão

\begin{abstract}
Since Manga and Cosplay was already embraced by the youth culture in Brazil, a teaching method for art classes aimed to children of all ages was developed using these elements for the internship program at The Chapecó Community College - Unochapecó. The combination of Manga's stunning visual art and the amusing performance of Cosplay proved to be quite appealing and helped engage students in art classes. The program was developed in stages carefully devised for each age segments, and they encompass interpretation of images and concepts, critiques and debates. However, due to the visual nature of this method, blind studants, who were not invested in Manga or Cosplay in the first place, could not reap the full benefits of the program, unfortunately, and felt somewhat excluded. As the method was applied, however, an idea emerged to revert the process and use arts to engage blind people of all ages in Manga and Cosplay culture. The above mentioned methods were developed and analyzed under internship supervision at CEIM Criança é Esperança, EEB Prof ${ }^{\mathrm{a}}$ Zélia Scharf and Associação de DeficientesVisuais do Oeste de Santa Catarina.
\end{abstract}

KEYWORDS:Mangá, Cosplay, art, teaching, social inclusion. 


\section{INTRODUÇÃO}

A partir de experiências obtidas na disciplina de Estágio em Artes Visuais, foram realizadas aulas de observação e docência em quatro níveis de ensino. Em primeiro momento, com turma do pré II, no CEIM Criança é Esperança, e com turma do $6^{\circ}$ ano do fundamental, na Escola de Educação Básica Prof ${ }^{a}$ Zélia Scharf. Em segundo momento, com turma do $2^{\circ}$ ano do Ensino Médio, também na EEB Prof ${ }^{a}$ Zélia Scharf, e turma do Ensino Não Formal, na Associação de Deficientes Visuais do Oeste de Santa Catarina.

Inicialmente foi pensado na temática do Mangá e do Cosplay em meio ao ensino de Artes, a qual ganhou o título: "Do Mangá ao Cosplay, processos criativos e performáticos no ensino das Artes". Apesar de serem temas não tão conhecidos por um público mais velho, devido à sua recente manifestação pelo mundo, estas nomenclaturas têmse desenvolvido em meio ao público juvenil, principalmente frequentador do Ensino Fundamental e Médio, ganhando espaço na sociedade brasileira (LINSIGEIN, 2007). O Mangá, de origem japonesa, corresponde à produção de histórias em quadrinhos do Japão, muito populares em sua região, mas, queganhou espaço pelo mundo, em especial no Brasil, onde encontra-se a maior colônia de japoneses e seus descendentes fora do Japão (MOLÍNE, 2004). O Cosplay, que significa "ação de se fantasiar", contém um significado muito mais abrangente, que percorre além da simples fantasia, e se situa no amor por um personagem e a sua transformação nele. De origem incerta, também ganhou força por meio das mais frequentes publicações de Mangá no Brasil, por incentivo de fãs, começa a fazer parte do cenário da cultura popular asiáticano país (NUNES, 2015).

Percebendo estes itens como conteúdos a serem explorados no ensino de Artes, e pertencentes à realidade dos estudantes, a qual, segundo Vigotiski (2003), deve ser pensada e considera pelo professor, idealizou-se uma proposta de aula que comunicasse linguagens em arte, promovesse o processo criativo com os educandos e melhor fundamentasse o Mangá e o Cosplay na realidade brasileira. "É necessário que a educação forneça um conhecimento sobre a cultura local, a cultura de vários grupos que caracterizam a nação e a cultura de outras nações” (BARBOSA, 1998, p.14), sendo assim, é importante a participação, no ambiente escolar, de itens que têm marcado a formação da figura brasileira, uma vez que esta é fortemente diversificada e aberta às mais variáveis culturas.

Metodologicamente, as ações foram pensadas conforme a abordagem triangular, visando trilhar três caminhos básicos: a leitura de imagem, a contextualização e a produção 
em artes (BARBOSA, 2002). Deste modo os conteúdos foram repassados e discutidos com os estudantes, gerando um processo de criação, o qual envolveu o desenho do Mangá e a ação performática com inspirações no Cosplay.

A partir das observações realizadas e dos resultados obtidos com a prática de docência, dois eixos de discussão foram pensados e analisados, tendo em vista o tema abordado e as turmas trabalhadas. O primeiro, com base nas falas de Luytein (2011), Carlos (2009), Nunes (2015), e outros autores que logo mais serão comentados, tem como seu meio central o fenômeno do Mangá, do Cosplay e a Arte em meio à juventude brasileira. Nesse caso específico, nas turmas trabalhadas nesse estágio na região de Chapecó. Foi pensado na presença e no desenvolvimento de ambas as temáticas no ambiente escolar, realizando uma comparação evolutiva dos níveis de ensino trabalhados, relacionando-os com fundamentos em Vigotski (2003), o qual traz o processo de desenvolvimento da criança e do adolescente, levando em consideração o meio o qual está inserida e os estímulos recebidos para sua formação. Pensando assim, o segundo eixo de discussão ganhou forças para ser desenvolvido, visto que o nível de Ensino Não Formal, apresentou nulos estímulos de desenvolvimento perante as temáticas visuais abordadas, gerando novas indagações sobre o Mangá, o Cosplay e as Artes Visuais como itens que ganham forma e força em nossa sociedade, devendoserpensados e percebidos para pessoa com deficiência visual também. Nesse segundo eixo, é abordada a arte educação para pessoa com deficiência visual e a apresentação de uma temática presente na sociedade atual, normalmente desconhecida para este público - o Mangá e o Cosplay - a partir das aulas de Arte.

\section{REFERENCIAL TEÓRICO}

\subsection{MANGÁ E COSPlay, A CULTURA POPUlar JAPONESA EM MEIO À JUVENTUDE BRASILEIRA}

Mangá são histórias em quadrinhos produzidas no Japão, as quais possuem características únicas, distinguindo-se das demais produções em quadrinhos. A palavra existe desde meados de 1814, onde o desenhista Katsuhika Houkusai a usou como nomenclatura para sua produção de imagens em sucessão e mais tarde, no início do século XX, foi adotada para nomear a grande produção em quadrinhos que se iniciava no país (MOLINÉ, 2004). O termo vem da junção de dois ideogramas man (involuntário) e ga (desenho, imagem) que 
juntos significam "imagens involuntárias, mas também pode ser compreendido como “moralmente corrupto, o que traduzido gera: "imagens irresponsáveis" (GRAVETT, 2006).

É no clima pós-guerra enfrentado pelo Japão, como válvula de escape para as tragédias e marcas deixadas em sua população que o Mangá passa a fazer parte daquela sociedade. Partindo dos fundamentos dos quadrinhos americanos, o Mangá obteve forma e voz ao receber itens do tradicionalismo e da perspectiva japonesa ganhando força e destaque a ponto de influenciar televisão e cinema. Osamu Tesuka, um dos grandes nomes do Mangá, motivado pela vontade de disseminar sobre paz e respeito à vida, após ter presenciado cenas fatais da segunda guerra mundial, dedicou-se em tornar o Mangá como parte da cultura japonesa. Para isto, usou-se de sua admiração pelo cinema, transformando o Mangá em uma história capaz de comover e cativar seu leitor. Seus desenhos passaram a imitar movimentos de câmera, além de serem recheados de itens como, efeitos sonoros, suor, lágrimas, olhos carregados de emoção, itens que estão presentes na composição das histórias até a atualidade, os quais humanizaram mais o desenho do Mangá, e foi capaz de influenciar inúmeros futuros autores de Mangá que tiveram contato com as histórias durante a infância (GRAVETT, 2006).

Enquanto o termo Cosplay, vem da mistura das palavras no inglês, costume (fantasias/trajes) e play (brincadeira, ação, interpretação), a qual surgiu a cerca de 30 anos, porém já domina grande parte do mundo, o qual tem interesse pelas ações de se fantasiar. Entretanto, os primeiros registros de sua existência, datam a década de 1910 com uma mulher não identificada usando trajes de uma personagem de tirinhas de jornal. Em 1939, o Cosplay tem seus primeiros registros de história na convenção de ficção científica Worldcon em Nova York, onde dois participantes, Myrtle R. Douglas e Forrest J. Ackerman, compareceram trajando roupas futuristas, o que marcou os eventos de ficção cientifica, assim como o início da prática Cosplay em eventos. No ano que se seguiu, vários participantes tomaram-nos como exemplo e levaram suas fantasias. Com isto, a organização do evento teve que improvisar uma exibição desses trajes. Nos eventos posteriores, estas competições foram formalizadas e prosseguem até atualidade nos diversos eventos que envolvem personagens (ASHCRAFT; PLUNKETT, 2014) ${ }^{1}$.

O Cosplay, não circulou apenas na região norte americana, no Japão foi onde ganhou forças e nome. Na década de 70 vários fãs dos Mangás e Animes (animação japonesa) passaram a se vestir conforme seus admirados personagens (ASHCRAFT; PLUNKETT,

\footnotetext{
1 Todas as citações de Aschraft e Plinkett, 2014, foram traduzidas pela autora.
} 
2014). Conforme já citado anteriormente, este período foi onde o Mangá expandiu-se e conquistou inúmeros leitores e fãs. Entretanto, até então, a ação de se customizar ganhava o termo Kazou, que tinha seu significado relacionado ao 'disfarce' e com isto não obteve destaque, pois foi considerada antiquada. Vários termos circularam e foram sugeridos, segundo Takahashi (apud ASHCRAFT; PLUNKETT, 2014), “[...] tínhamos ouvido a palavra inglês 'costume' e eventos com nomes como 'show de fantasias', 'kazou show', 'ação herói' e outros.” (p.19). Conforme a região, inúmeras traduções e nomenclaturas eram usadas para nomear os eventos que recebiam o Cosplay. Mas, foi em 1983 que Nobuyuki Takahashi, publicou um artigo, onde cobriu inúmeros fãs de Mangás e animes trajando seus personagens favoritos, no evento Comiket em Tóquio e nomeou aquela ação, pela primeira vez, como Cosplay. O termo então foi bem aceito, expandiu-se e tem dominado o mundo até hoje (ASHCRAFT; PLUNKETT, 2014). Para Takahashi (apud ASHCRAFT; PLUNKETT, 2014):

Cosplay é a expressão de amor de um fã por seu personagem favorito [...] Desenhar uma peça de arte, escrever uma história, um filme de animação e mostrar isso para os outros é uma manifestação desse amor. O Cosplay é uma dessas expressões em que os fãs usam todo o seu corpo. (p. 20)

Muito além de uma prática que ganhou forças nas últimas décadas e ainda está se espalhando pelo mundo, mais que uma ação fantasiosa, o Cosplay tem sido um hobbie, valorizado pelos fãs, os quais devotam tempo e amor para construção de seus trajes e planejamento de suas performances nos eventos (NUNES, 2015).

Sendo tão forte em seu país de origem, o Mangáe o Cosplaydificilmente se desvinculariam dos japoneses, contribuindo assim para imersão e influência deste em nosso país. Uma vez que, segundo Moliné (2004), o Brasil é:

Onde reside a maior colônia japonesa fora de sua terra natal, principalmente na área de São Paulo. Além de contar com vários desenhistas locais de ascendência nipônica que introduziram o 'estilo Mangá', a partir dos anos 60, na produção nacional de HQ, o Brasil foi o primeiro país ocidental em que surgiu uma associação dedicada aos Mangás: a Abrademi (Associação Brasileira de Mangá e ilustração), fundada em 1978. Naquele mesmo ano Osamu Tesuka visitou o Brasil, convidado pela Fundação Japão (p. 62).

Inicialmente o Mangá veio ao Brasil por meio desses imigrantes que formaram as colônias no país, os quais gostariam de ter um contato com sua linguagem natal e repassá-la para suas futuras gerações nascidas no novo país, principalmente por se tratar de uma 
linguagem mais simples, mais atrativa às crianças e jovens, e possuidora de legendas que facilitavam a compreensão de ideogramas (formas que compõe o alfabeto japonês) mais complexos, o que reforçava as aulas de japonês, e o que mais tarde serviu de impulso para a recepção do Cosplay (LUYTEN, 2011).

Por volta de 1960 a cultura popular japonesa espalhou intensamente no território brasileiro, trazendo consigo os Animes e os Mangás. Conforme Gusman (2005 apud. Santo, 2012):

\begin{abstract}
Na década de 1960, os animes, ou desenhos animados japoneses começam a serem exibidos no Brasil e o resto da população finalmente conhece e fica fascinada com a estética do Mangá (ou seja, impressionados com os olhos grandes dos personagens e suas expressões exageradas), sem conhecer ou, muitas vezes, sem ao menos saber o que era um Mangá, pois ainda não havia publicações em português (...). Só a partir de 2000 é que os quadrinhos surgiram no mercado com formatos mais fiéis à forma original, com leitura no modo oriental e mantendo as onomatopeias, sendo acrescentadas pequenas notas explicando o seu significado (p. 5).
\end{abstract}

No Japão é difícil desvincular a relação do Mangá com as animações japonesas, as quais são chamadas de Animes, em nenhum outro país este vinculo é tão forte e fundamentado (MOLINÉ, 2004). Conforme Moliné (2004), “quem consome Mangás, quase inevitavelmente, também consome Anime" (p.47). Com isso, é quase impossível falar de Mangá e sua influência e não assimilar o público como consumidor dos animes,assim como este mesmo público raramente se desvincula da ação Cosplay, a qual com a expansão editorial do Mangá e da cultura japonesa nas terras brasileiras por volta da década de 90 começou a tomar forma no país. Em 1996, em São Paulo, o MangaCon (Convenção Nacional de Mangá e Animê) é nomeado como o primeiro evento do país onde se podia ver a presença de cosplayers (nome dado para as pessoas que realizam a ação Cosplay), porém outras fontes relatam que, desde a década de 80 , já havia fãs vestidos de personagens, entretanto não carregavam a nomenclatura Cosplay, a qual ainda era muito nova para época (NUNES, 2015).

O Cosplay, trata-se de uma das modalidades de comunicação de massa da cultura oriental, assim como Mangás, Animes e animesongs. Os formadores desta cultura vão além da descendência japonesa e permeiam a diversidade cultural brasileira, os chamados otakus, fãs e admiradores de produtos nipônicos os quais interagem entre si e dominam o universo simbólico do grupo (NUNES, 2015). E são estes que desde a década de 1990 produzem e 
participam do fenômeno Cosplay, realizando diversos eventos que contemplam inúmeros itens da cultura popular japonesa (COELHO, 2008).

Conforme Nunes (2015), "muitos dos eventos que se tornaram comerciais nasceram de clubes de amigos e de encontros estimulados apenas pelo desejo de compartilhar as preferências pelos animes e Mangás” (p.34). De 1996 até a atualidade, inúmeros eventos, os quais comportam a ação Cosplay foram criados e espalhados por todo o país, principalmente nas capitais, onde percebe-se um grande índice de eventos. Como exemplo, no Rio de Janeiro, em 2013, encontrou-se chamadas para tais eventos em quase todos os fins de semana (NUNES, 2015).

Em cada evento, são realizadas competições entre os cosplayers, os quais devem encenar ou apenas desfilar com o figurino de seu personagem. Entretanto, unicamente no Brasil, essas competições ganharam uma característica inovadora e forte dentro dos eventos: o Brasil é o único país a ter a modalidade de atuação livre, em que se cria uma nova cena para se atuar com aquele personagem, sem deixar de lado suas principais características (NUNES, 2015). "O coordenador de eventos explica que a categoria livre é exclusiva do Brasil: 'cada país tem suas regras [...] no Brasil, as pessoas gostam de encenar” (NUNES, 2015, p.39).

Vale ressaltar que, apesar da origem e motivação desses eventos estarem estreitamente relacionadas com o Mangá e os Animes no Brasil, atualmente, a variedade de personagens desses eventos, abrange inúmeras histórias em quadrinhos, filmes, jogos e celebridades, assim como as características e situações dos eventos ganham particularidades conforme a região brasileira a qual está inserida, tornando-os, assim, ações mais próximas à cultura brasileira (NUNES, 2015).

O Mangá tem se erguido com grande influência na leitura entre crianças e adolescentes (LUYTEN, 2011).Linsigein (2007), reafirma esta atenção da juventude em relação ao Mangá ao falar da grande massa de leitores de quadrinhos, "estes fazem parte de um público na maior parte das vezes jovem, o mesmo que frequenta o ensino fundamental e médio" (p.1). Do mesmo modo, esta população leitora dos Mangás desenvolve um forte desejo em participar de eventos que comportem o Cosplay, tornando-se o maior publico presente, apesar de encontrarmos pessoas mais velhas (em especial parentes próximos dos jovens frequentadores) também aderindo à cultura Cosplay (NUNES, 2015).

O Cosplay no Brasil, conforme os autores citados acima, percorre algumas cidades e se expande com o passar do tempo, sendo fenômeno em meio aos admiradores do Mangá e da cultura nipônica. Para Carlos (2009), “a perspectiva que podemos fazer para o futuro é que os 
Mangás se tornarão ainda mais numerosos no Brasil” (p.14.) Com isso, o Cosplay também ganhará forças e sustentação no país. Nesse contexto, Coelho (2008) trata isto como um fenômeno psicossocial rico em uma identidade local, e que requer um contato considerável com a história desta cultura com nosso país. O que nos permitiu pensar em aulas, neste caso de arte, que abranjam a ideia do Mangá e do Cosplay, como meios diferenciados para se propor atividades em artes. Incentivando assim, os discentes a conhecerem melhor esta cultura a qual tanto admiram, e perceberem sua ligação histórica com a cultura brasileira e as influências que tem inserido no país.

\subsection{DO DESENHO A PERFORMANCE: PROCESSOS CRIATIVOS E PERFORMÁTICOS NO ENSINO DAS ARTES A PARTIR DO MANGÁ E DO COSPLAY.}

Para esta ação, o Mangá e o Cosplay foram pensados e interligados com linguagens específicas em arte, o desenho e a performance. Ambas foram abordadas de modo que uma dependesse da outra, ganhando inspirações na proximidade do Mangá e do Cosplay.

O Mangá é proposto e construído por técnicas de desenho, qualificadas no decorrer da história do Japão para gerar figuras, imagens, personagens capazes de relatar os interesses de seu autor. Em meio à arte, parafraseando Derdyk (1994), muito além do lápis e do papel, o desenho está envolto na sociedade, na história, na cultura de cada nação, moldando-se conforme a época, tornando-se forma de conhecimento, expressão e comunicação. Uma linguagem antiga, porém permanente, a qual percorre anos, a produção em artes visuais é o exercício da inteligência humana. "O desenho participa do projeto social, representa os interesses da comunidade, inventando formas de produção e de consumo" (DERDYK, 1994, p.37). O desenho é capaz de trazer em si, histórias de povos e exemplificações culturais. Comunicando e expressando modos de ver, hábitos e costumes. Possuído por todos, seja o artista ou o artesão, o desenho expõe significados atribuídos às coisas pelo homem (DERDYK, 1994). Visto isso, é possível perceber o desenho como meio rico em expor a cultura de uma determinada sociedade, fomentando sua ligação com o Mangá no ensino de artes, por meio de assimilações técnicas sociais e culturais do desenho.

Ao se pensar no desenho como técnica presente em Artes Visuais,é notável a ligação destes há muitos anos. Para Roig (2009), “Qualquer expressão artística se vale do desenho como meio para entender o projeto inicial" (p.6). O desenho além de atuar como trabalho final, também pode ser percebido como um auxiliador, o início, o planejamento para demais 
se pensar em outras técnicas (ROIG, 2009). Parafraseando Pereira (2007) é com o desenho, utilizando-o de diversas formas, e com inúmeros materiais, que o aluno tem seu primeiro contato com as artes visuais, justamente pela acessibilidade que oferece e pela sua presença na sala de aula. Com isso, é importante pensar meios atrativos e diferenciados para explorar o desenho e não o tornar uma produção comum e sem gratificações. Então, porque não, usá-lo juntamente com o Mangá como meio para incluir novos conteúdos e objetivos no ensino de artes? O poder do desenho, seja nos quadrinhos ou animações, deve ser considerado, uma vez que está tão presente na rotina da criança e do adolescente. "O desenho animado é um bom meio de estimular o interesse. É um meio ideal para ensinar" (Disney, 1994, apud Santo, 2012).

É perceptível o modo que o desenho, a animação e os quadrinhos possuem de cativar diferentes gerações de crianças e adolescentes, os quais estão presentes em nossas salas de aula. Em pesquisa realizada pelo Instituto Pró-Livro (2008), citada por Santo (2012), "Especificamente entre estudantes até a quarta série, os quadrinhos são o terceiro item mais mencionado" (p.3). Porém, como a escola tem recebido este item - o desenho animado, ou quadrinhos - como parte da leitura de seus alunos? Santo (2012) cita Almeida (1994. p.7) que discorre sobre esta relação, comentando que:

Parece que a escola está em constante desatualização, que é sublinhada pela separação entre a cultura e a educação. A cultura localizada num saber-fazer e a escola num saber-usar, e nesse saber-usar restrito desqualifica-se o educador que vai ser sempre um instrumentista desatualizado (ALMEIDA, 1994, p.7, apud SANTO, 2012. p. 3)

A autora refere-se a essa fala, abordando a falta de temas atuais, por vezes distantes das salas de aula. O Mangá, assim como as demais culturas de mídia, é muito popular em meio ao público juvenil, o qual pertence, em sua maioria, ao nível de ensino médio (LINSINGEN, 2007), portanto lhe compete ser uma ferramenta pedagógica não apenas para a percepção do desenho, mas para outros diversos temas e experiências a serem ofertadas aos discentes.

Coelho (2005), fala do Mangá além de uma forma comunicativa, mas um expositor de sensações e vivências humanas, podendo mostrar realidades através das imagens. Linsingen (2007), reafirma isso comentando o Mangá como uma ferramenta pedagógica recheado de diversas funções: 
[...] função ilustrativa, pois representam, de forma gráfica, uma situação ou um fenômeno; explicativa, pois precisam contextualizar, para melhorar a compreensão da história, a situação de forma completa, integralizada; motivadora, pois inserem a situação no enredo sem explicação prévia, motivando/ forçando o estudante a pesquisar melhor o tema para ser capaz de "acompanhar" a história; e instigadora, dada a proposta explícita de apresentar ao leitor, durante a narrativa, uma questão que o faça pensar sobre o assunto (p.6).

No contexto das aulas de Artes, o Mangá pode ser abordado como conteúdo de desenho da figura humana a partir de técnicas de ilustração, como a prática de desenho de criação, aproximando crianças e adolescentes que já desfrutam da admiração pelo traçado oriental das práticas de desenho nas aulas de Arte, assim como, no caso deste relato, além de mera ilustração ou repasse de técnicas, pode participar de um processo criativo na sala de aula.

O Cosplay é, então, um envolvimento da pessoa com um personagem fíctício, seja do Mangá, dos Animes ou dos diversos tipos de quadrinhos. Trata-se de uma ação performática dentro de eventos específicos para isso. Para Nunes (2015), "Fazer Cosplay diz respeito a uma prática comunicativa, cultural e de consumo, em que os participantes não apenas se vestem, mas, sobretudo, atuam como personagens das mais variadas narrativas" (p.24).

Ao se pensar na história da arte e envolvê-la com a prática Cosplay,é por meados do fim da Segunda Guerra Mundial, aproximadamente a mesma época em que o Mangá se destacou no Japão, que o corpo passa a ser notado e estudado como meio para expressão artística, o que gerou diversos movimentos, entre eles a performance. Após as experiências traumatizantes do pós-guerra na Europa, passou-se a atentar para novos pontos que antes não recebiam atenção (PIANOWSKI, 2007). Buscou-se a liberdade, inclusive a liberdade do corpo, que passou a ser uma matéria recheada de sentimentos, uma propriedade de domínio (PIANOWSKI, 2007). É através disso que os intelectuais e os artistas começam a atentar para “O corpo e todos as suas secreções como zona artística, território da ação, dos fenômenos, dos processos e da própria obra de arte, como é o caso do acionismo vienense, da performance e da body-art" (PIANOWSKI, 2007, p. s/n).

É pensando neste estado do corpo em meio à arte que se questiona: Como abordar o corpo arte no ambiente da sala de aula, respeitando a diversidade cultural, as diferentes linhas de pensamento e reações perante a visualização corporal? O Cosplay, foi uma das alternativas de levar às artes visuais um processo criativo que envolvesse o corpo. "Na arte corporal e de 
performance a figura do artista é ferramenta para a arte. É a própria arte" (GREGORY BATTCOCK apud. SANTOS, 2008. p. 2). Levando essa fala em consideração, de forma sucinta busca-se comparar o uso da figura de si mesmo como arte performática, com a prática do Cosplay, em que o desenho, o personagem admirado, passa a ser identificado e encarnado pelo sujeito, o qual assimila suas atitudes perante todos (AVARI; ROSA, 2011). Acrescentase a essas citações um trecho publicado por Renato Cohen (2002) em seu livro "Perfomance como linguagem criação de um tempo-espaço de experimentação", o qual fala sobre o artista performer Joseph Beuys e a relação da pessoa existente com a pessoa proposta em performance:

Na performance existe uma ambiguidade entre a figura do artista performer e de uma personagem que ele represente. Na performance de Joseph Beuys quem está lá é o próprio artista e não alguma personagem. É importante distinguir, no entanto, que à medida que Beuys metaforicamente está representando (simbolizando) algo com suas ações, quem está lá é um "Beuys ritual" e não o "Beuys do dia-a-dia" (COHEN, 2002, p. 58).

Joseph Beuys, artista performático exemplificado na citação, tem um trabalho que visa o retomo ao lado criativo do homem. Suas experiências envolvem a arte por meio das ações. Procurava-se um diálogo mais próximo com o outro e para isso as ações apareceriam para traduzir suas ideias de vida e arte ao espectador. Beuys confiava também que a arte era capaz de transformar o ser humano, que passaria a questionar suas verdades absolutas, o que chama de escultura social, e considera capaz de modificar qualquer ambiente, inclusive o da sala de aula (PEREIRA, 2014). Beuys não é o personagem que representa, mas é Beuys que ali está, um Beuys diferente que pretende comunicar utilizando seu corpo e suas ações como linguagem. O Beuys criado no momento da performance é um novo Beuys, uma espécie de personagem performático, que não se classifica simplesmente como um personagem de teatro, mas como um personagem performático, o qual Alves (2010) distingue:

Na performance o ator não está comprometido com a estrutura em torno do drama. Sua meta é a articulaçãodo objeto, do tempo e do espaço através da ação, valorizando o aqui-agora. A ficção mistura-se com a realidade e assim o ator faz a ligação entre as esferas vida e arte,transitando, o seu corpo, nessa zona de indefinição (ROSSINI, 2005). Essa zona de identificação se caracteriza pela ruptura com a representação (ALVES, p. 5. 2010). 
É de notável semelhança a proposta de personagem da performance com a ação Cosplay, a qual, conforme já aqui citado, promove o surgimento de um personagem que não deixa de ser a pessoa que realiza a proposta, e se adequa ao momento e ambiente em que se situa. Ao falar sobre Joseph Beuys e o personagem, é possível percebermos na fala de Pereira (2014), uma preparação muito semelhante ao Cosplay: "nas ações, a presença do artista é total. Ele diz apresentar-se sempre carregado de uma 'energia' e com uma preocupação minuciosa com todo o corpo - rosto, mãos, boca, olhar -, pois pretende uma comunicação direta com o espectador" (p.96). Semelhantemente, Nunes (2015) descreve o corpo do cosplayer:

[...] é corpo-mídia e multiplataforma para onde, simultaneamente, confluem e dispersam narrativas e personagens midiáticos ao serem materizalizados e performatizados em tecidos, materiais novos ou reciclados, perucas e maquiagens coloridas, rostos inteiramente pintados, máscaras de personagens amorosos e repugnantes [...]. Uma miríade de artefatos, gestos e vozes compõem o Cosplay, deixando, a todo momento, a inscrição da atividade lúdica e do prazer nestas feituras. A cena Cosplay revela sensibilidades performativas, especialmente considerando os corpos hiperbólicos que lá transitam [...] (p.46 e 47).

Percebe-se que, assim como na performance, o Cosplay vai além de uma fantasia ou de um personagem teatral, abrangendo figurino e atuação, porém envoltas na realidade de seu feitor e da sociedade que está a sua volta. A ação na performance ganha um caráter éticoestético que ultrapassa a construção de uma personagem ou de um fluxo de intensidades energéticas. A performance parece estar preocupada em reconhecer e investigar a relação entre sujeito e mundo contemporâneo (PEREIRA, 2014). Essa relação ainda se faz presente em meio à cultura Cosplay, a qual não se limita a eventos destinados para a ação, mas expandindo-se para ruas e locais sociais comuns, que passam a ser palcos para o espetáculo, libertos de roteiros e expostos a uma nova realidade, contemporânea e improvável (NUNES, 2015). Ainda conforme Nunes (2015), “o Cosplay configura um processo de uso, apropriação e ressignificação de enredos e personagens, em qualquer situação, da recriação das histórias [...] à confecção do indumento" (p. 45). Trata-se de uma prática mais complexa do que a ação de se fantasiar para algum momento, e passa a ser uma experimentação de outro ser dentro de si mesmo, exposto para o mundo com a carga cultural local, juntamente com a força do personagem. O que nos permite pensar o Cosplay como ação dentro da educação formal e não formal, para pensar e refletir sobre a performance e o corpo como arte. 
A partir disso, o Mangá e o Cosplay foram pensados como itens a serem abordados na sala de aula, de modo a gerar uma proximidade com a realidade dos alunos. Gerando experimentações de um processo artístico no ensino de Artes, que envolveu a construção de um personagem, semelhante aos vistos em Mangá, posto em uma realidade contemporânea a dos discentes, que deveria ser pensado e proposto para originar um personagem performático, que atuaria em meio à comunidade a qual aqueles alunos se situavam.

\section{METODOLOGIA: PROCESSO CRIATIVO EM ARTES}

O Processo criativo baseia-se em articulações entre saberes históricos pertencentes a uma determinada cultura. Cultura a qual rege toda e qualquer criação, a partir dos diálogos estabelecidos no decorrer da história de um indivíduo, juntamente com os diálogos em sala de aula. Leva-se em consideração a dinamicidade da cultura, uma vez que fronteiras geográficas não limitam sua interação, visto que um sujeito pode pertencer a diferentes grupos simultaneamente. Desse modo, o processo artístico de cada sujeito vem carregado de signos e símbolos o que gera uma identidade construída entre muitos entrelaçamentos. Tais características podem estar presentes entre os perfis dos alunos em sala de aula (PEREIRA, 2007).

Para Vigotski (2003), “o comportamento humano se forma a partir das peculiaridades e condições biológicas e sociais de seu desenvolvimento" (p.75). Construindo assim, indivíduos cheios de saberes e vivências a serem consideradas e pensadas no ambiente da escola. Afinal, parafraseando o mesmo autor, esse sistema de reações é determinado pela construção do ambiente em que esse indivíduo cresce e se desenvolve, dando um caráter social para a educação, ressaltando que as vivências dos educandos são de extrema importância para o trabalho pedagógico. Cabe à figura do professor estruturar esse ambiente conforme as necessidades de seus alunos, permitindo uma formação rica em experiências pessoais, que vão além de perceber coisas, mas tornar o aluno capaz de interagir e produzir novas reações e formas de conduta (VIGOTSKI, 2003). É possível acrescentar a essa ideia a fala de Pereira (2007), que afirma que "A sala de aula pode ser um poderoso espaço de criação. Partindo de propostas pedagógicas bem estruturadas, os alunos se capacitam a criar soluções para problemas diversos, formular novas hipóteses, reinterpretar velhas proposições" (p.11). 
No ambiente escolar, o aluno encontrará um poderoso espaço criativo que o capacitará parareinterpretar a si mesmoe buscar soluções para hipóteses. O ambiente da sala de aula gera a expectativa de corresponder com o que fora solicitado, entretanto, o resultado não se desvinculará da marca pessoal do aluno. Mesmo que ele troque sugestões e avaliações entre os colegas, seu trabalho ainda permanecerá particularizado, embora enriquecido com o aumento da troca de relações, com o conhecer o outro. O processo criativo dar-se-á com a cultura, na soma entre as diversas interações em sala de aula, aluno-professor ou aluno-aluno (PEREIRA, 2007). Com isso, uma ação proposta na disciplina de Artes Visuais, deve pensar na figura do aluno, e suas relações com a sociedade e o mundo, no ambiente da sala de aula e nas possíveis trocas de saberes que instiguem um processo criativo rico em resultados ecolaborem na formação dos educandos.

Para basear a ação metodológica, utilizou-se a abordagem triangular da autora Ana Mae Barbosa (2002), a qual fomenta um ensino de Artes que qualifique o aluno a perceber imagens de forma crítica, lendo-as tanto na história da arte quanto em seu cotidiano, de modo que a ação docentese inspire em três momentos: a leitura de imagem, a contextualização e a produção artística. Fundamentando assim, um processo artístico consciente e respaldado, com análises e novas percepções sobre o mundo, a contemporaneidade e as artes, o que provocará novos sentidos perante o universo da leitura visual.

A pesquisa teve como instrumento a observação, a qual "É um defrontar-se com a realidade. [...] É perceber, aprender a ver, detalhar, fazendo relações com as experiências pessoais, os conceitos e etc., de maneira ordenada e sistemática, o que permite conclusões e posicionamentos críticos" (FERRAZ; FUSARI, 1993, p.118). Além disso, foram usados registros iconográficos das produções em sala e análise de conteúdos de fontes secundárias (obras, livros, apostilas, teses...). Isso se deu a partir das observações e docências realizadas na disciplina de estágio II e III, em turma do pré II, composta por quinze alunos com faixa etária de 5 a 6 anos de idade no CEIM Criança é Esperança; com turma do $6^{\circ}$ ano, com faixa etária de 12 a 13 anos, e do $2^{\circ}$ ano do Ensino Médio, com faixa etária de 15 a 16 anos, as quais continham 27 alunos e pertenciam à Escola Básica Prof ${ }^{a}$ Zélia Scharf; e turma do Ensino Não Formal, composta por 11 alunos com idades variadas entre 7 a 50 anos.

Pensando dessa forma, de modo geral, as docências foram divididas em cinco etapas que permaneceram em todos os níveis de ensino, porém foram abordadas de modo diferenciado, conforme a necessidade de cada turma. Em primeiro momento o Mangá e o Cosplay foram contextualizados, tanto no cotidiano do aluno, do Brasil e do mundo, por meio 
de mostra de slides e conversas com os discentes. No segundo momento, foram apresentados artistas modernos e contemporâneos que correspondessem à linguagem do desenho e da performance, as quais foram comparadas com o Mangá e o Cosplay a partir dos trabalhos dos artistas e argumentos aqui referenciados. Na terceira etapa, atividades de ilustração a partir do Mangá foram brevemente repassadas, promovendo ao aluno um contato mais próximo com o Mangá e com seu personagem, iniciando o processo de criação performático. Na quarta etapa, os alunos puderam reunir-se para planejar suas ações performáticas a partir do personagem criado. Por fim, o quinto momento, constou a mostra dos resultados das performances, em alguns casos, no ambiente de aula, e em outros por meio de gravações da ação fora do espaço da escola.

A abordagem deste relato teve caráter qualitativo, visto que trouxe hipóteses e teorias sobre as questões observadas, as quais segundo Miranda (2007) têm por objetivo:

[...] descrever uma situação, um fenômeno ou um grupo de itens (pessoas ou coisas); gerar hipóteses de trabalho cuja verificação depende, no âmbito da pesquisa qualitativa, de tratamento específico ou, no âmbito da pesquisa quantitativa, de indicadores preliminares para estudos posteriores de caráter mais aprofundado; contribuir para geração de teorias a respeito da questão sobre exame. A pesquisa qualitativa é globalizante, holística. Procura captar a situação ou fenômeno em toda a sua extensão (p.44).

Uma vez que a pesquisa buscou e provocoureflexões, questionamentos e problemáticas acerca do Mangá e o Cosplay como ferramentas no ensino de Artes, e se utilizou de tentativas e eliminação de erros por meio da observação e da experiência em sala de aula, o método usado foi o hipotético-dedutivo, o qual Miranda conceitua: "Toda pesquisa tem sua origem num problema para o qual se procura uma solução; através de tentativas (conjecturas, hipóteses, teorias) e eliminação de erros; Chamado 'método de tentativas e eliminação de erros" (MIRANDA, 2007, p.15).

Por fim, foram analisados os diálogos, as perguntas, os resultados e toda troca estabelecida na experiência do estágio, situando idade, deficiências e potências dos alunos observados perante o tema proposto.

\section{ANÁLISES E RESULTADOS OBTIDOS}

A partir do desenvolvimento das ações com os diferentes níveis de ensino trabalhados, algumas peculiaridades foram percebidas e nos levam a algumas reflexões sobre 
os temas abordados, o indivíduo e a sociedade, e a arte e seu ensino. Foi possível pensar e perceber os resultados obtidos em níveis de evolução, com exceção ao nível não formal, o qual obteve comportamento bastante distinto das demais realidades. Os resultados e análises podem ser observados em dois momentos. Um momento percebe-se o Mangá e o Cosplay como um conhecimento que evolui conforme a idade do aluno e as influências recebidas principalmente pelo ambiente escolar. Em um segundo momento, o Mangá e o Cosplay em meio à acessibilidade e diversidade física humana, com um público que tem um difícil acesso e desconhece totalmente a cultura popular asiática, a qual tanto cresce em meio à população brasileira. Neste momento, não serão descritas todas as atividades realizadas com os grupos aqui apresentados, mas sim dar-se-á ênfase para a recepção do Mangá e do Cosplay por essas turmas, o processo de criação como um todo, envolvendo a criação do personagem, a ação do Cosplay performático e os resultados dessas ações nos alunos.

Inicialmente, com o que chamaria de nível 1, tanto para dificuldade e conhecimentos perante o assunto, o ensino infantil, apresentou a sensação do desconhecido acompanhado de um forte interesse em descobrir os temas que seriam abordados. Ao falar sobre o Mangá e o Cosplay, e inserir o desenho e a performance de forma discreta por meio de atividades lúdicas, a turma em questão (com exceção de um aluno que mostrou conhecer rasamente sobre o tema), desconheceu as temáticas, assimilando-as como uma novidade muito atraente. A curiosidade tomou conta das ações, os quadrinhos e os itens para montagem de um Cosplay surgiram como brincadeira, e atividades que envolveram o desenho e a performance discretamente foram brevemente introduzidas em meio as ações do desenhar personagens, e o Cosplay, permitindo assim, explanar sobre a cultura asiática em meio a nossa sociedade, conceituar Mangá e Cosplay sucintamente, e promover ações semelhantes a prática Cosplay.

$\mathrm{O}$ resultado das atividades limitou-se a pequenos e rápidos desenhos, assim como uma difícil ligação entre as atividades de criação do personagem com a ação Cosplay, as quais permaneceram fragmentadas, percebendo-se assim uma frágil criatividade, compensada pela ausência do medo de criar e imaginar. Conforme Vigotski (2009),“A criança é capaz de imaginar bem menos do que um adulto, mas ela confia mais nos produtos de sua imaginação e os controla menos" (p.46). O que justifica a liberdade encontrada neste nível, acompanhada, porém, da limitação em pensar e problematizar personagens, uma vez que ainda conforme Vigotski (2009), na infância, a criança está em um forte processo de formação, que se define conforme as experiências vividas, que respalda a imaginação e a criatividade. Entretanto, pelas poucas vivências obtidas, se comparada a um adolescente ou um adulto, a criança tem 
pobres índices de criação e imaginação, o que se percebe com um dos trabalhos resultantes. A atividade consistiu na ideia de personagem criada pelo aluno e no desenho construído pela autora, como forma de presentear os alunos participantes, apresentando características simples e sem justificativas, as quais eram fortalecidas e motivadas pela diversão. O aluno B (imagem 1) alegou que seu personagem salvaria o mundo com o poder da seriedade, deixando as pessoas mais sérias, um ninja resolveria qualquer situação. Ao ser questionado pela motivação em construir o personagem, o aluno alegou que sempre quis ser um ninja, e que sua mãe já havia the feito uma roupa especial para que ele pudesse brincar.

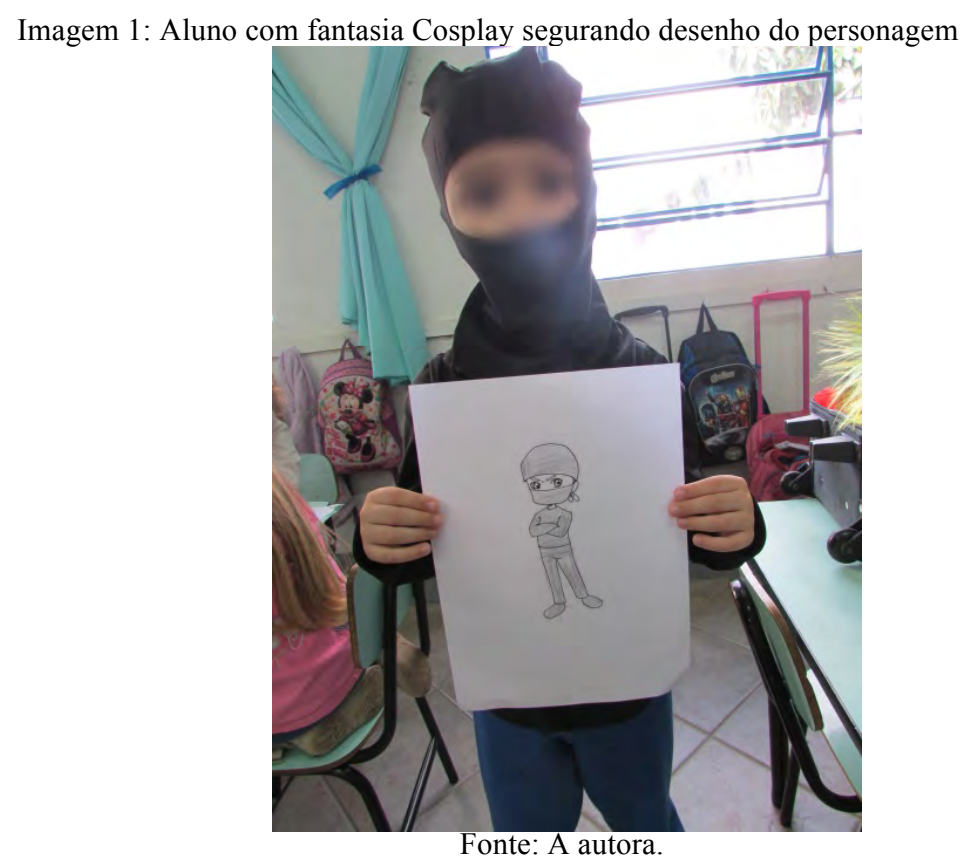

No segundo nível de ensino, referente ao $6^{\circ}$ ano do Ensino fundamental, o qual para Luytein (2011) já faz parte de um público que conhece e vive o Mangá e o Cosplay, e que para Nunes (2015) em sua maioria encontra-se em capitais brasileiras, onde normalmente esse conhecimento e vivência são estimulados e incentivados por meio de inúmeros eventos de Mangá e Cosplay. Porém, não se exclui a possibilidade de que fora das capitais, mesmo sem eventos e incentivo direto do consumo do Mangá e o Cosplay, haja adolescentes cativados e conhecedores desta cultura, o que foi perceptível neste nível de ensino.

Toda a turma alegava não saber o que era Mangá, porém por meio de observações percebeu-se que os alunos possuíam o estilo em seu traço, e ao expor imagens de Mangás e 
animes e visualizarem-nas, declararam conhecer histórias em quadrinhos produzidas no Japão, ter acesso a imagens de personagens em Mangá e assistiam ou já haviam assistido algum tipo de Anime, a maior parte pelo uso da internet. Com isso, fez-se necessário construir um conceito juntos sobre o assunto, de modo que os educandos pudessem relacionar seus conhecimentos com as definições, histórias e contexto.

Sobre o Cosplay, neste nível de ensino, apesar de não usarem o termo para definir a ação, compreendiam e conheciam parte do processo Cosplay. Com esta situação, abordar artistas e compará-los ao Mangá e ao Cosplay obtiveram uma boa recepção, permitindo uma fácil assimilação da criação de personagens, do vestir-se de personagem, e de contextualizar esse personagem na sociedade. A partir deste nível, percebeu-se sobre a fala de Vigotski (2009), que “À medida que a maturidade se aproxima, começa também a amadurecer a imaginação e, na idade de transição - nos adolescentes, coincide com a puberdade -, a potente ascensão da imaginação e os primeiros rudimentos de amadurecimento da fantasia unem-se" (p.45). Diferente do primeiro nível, este, além de já ter experiências com o Mangá e o Cosplay, apresentou um amadurecimento imaginário e criativo, percebendo melhor a sociedade e a arte.

Estimulados com atividades de repasses técnicos do desenho, os estudantes, em sua maioria expuseram suas ideias por meio do desenho e partiram para criação de seus personagens para performance, os quais continham problemáticas sociais, e condiziam com o ambiente que foram situados na performance. Notou-se que a ligação entre as temáticas abordadas já estava bem definida, tornando a proximidade do desenho com a performance semelhante a do Mangá com o Cosplay. Como no caso do grupo A (imagem 2), pensando na figura do consumismo e padrões de beleza, criou personagens que frequentariam o ambiente de um Shopping, porém causariam estranhamento aos demais, por não se incluírem nos padrões estabelecidos. Segundo relatos do grupo, a ação com o tema escolhido teve seu início quando alguns integrantes do grupo sentiram-se envergonhados em expor-se fora do padrão no ambiente do Shopping, o que os fez perceber que a problemática escolhida, além de presente na sociedade deve ser pensada na individualidade do cidadão. 
Imagem 2: Desenho de personagem e ação Cosplay

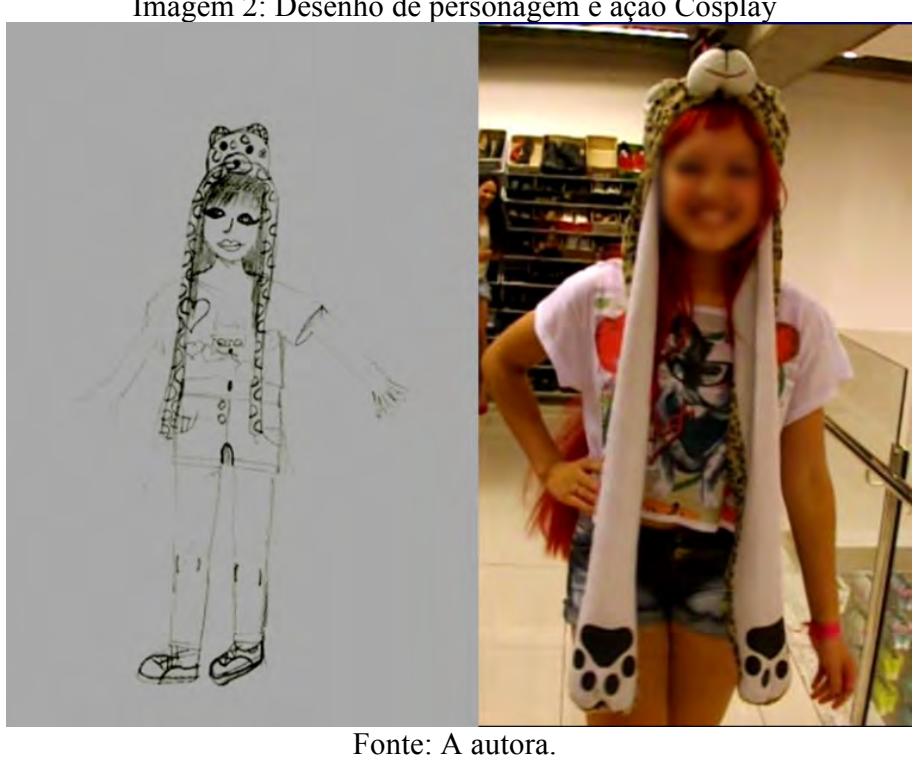

Em terceiro nível, correspondente ao $2^{\circ}$ ano do Ensino Médio, a maior parte dos discentes, com raríssimas exceções, conheciam conceitos sobre o Mangá e o Cosplay, e já possuíam relações e referências com o assunto. O que fundamenta a fala Linsigein (2007), que se refere a este nível como um dos maiores consumidores do Mangá.

Ao questioná-los sobre o conceito de ambos, vários alunos respondiam conceituando-os e exemplificando, mostrando um forte domínio sobre a cultura asiática. Entretanto, nenhum dos alunos dispunha do conhecimento sobre a influência asiática no Brasil, suas miscigenações e da forte presença de japoneses e seus descendentes no Brasil. O que para Ana Mae Barbosa (1998) é importante que a educação seja o espaço da diversidade cultural, principalmente dos grupos que caracterizam uma nação e de outras nações também. Sendo assim, necessário participar no ambiente da escola itens que têm marcado a formação da figura brasileira, visto que está fortemente diversificada e aberta as mais variáveis culturas.

Em especial, a temática do Cosplay, fora tratada como um forte desejo e "sonho a ser realizado" conforme a fala de alguns alunos. Relacionar o Mangá e o Cosplay, com a produção em artes visuais, inicialmente fora mais difícil, pois parte da turma, acreditava que a relação não seria produtiva, preferindo a "pureza" dos termos. Entretanto, isto foi melhor aceito durante o processo de prática, planejamento e análise das ações a serem realizadas.Conforme Ferraz e Fusari (1992), é papel do educador perceber os interesses, as vivências e saberes dos alunos, identificando o que melhor deve ser aprendido e analisado pelos mesmos, educando além da inserção de um novo conteúdo, mas abrangendo o educar do olhar, do pensar e se portar em meio a sociedade. 


\section{EDUCAÇÃO, ARTES}

E INCLUSÃO

A partir deste nível, ainda conforme Vigotski (2009), percebe-se que quanto mais próximo da fase adulta, mais criatividade e imaginação fazem parte do indivíduo, porém o medo de produzir e expor suas ideias é fortemente percebido. Apesar do domínio maior sobre os conteúdos abordados, e os materiais a serem assimilados, nesta fase o aluno necessita de um incentivo maior em acreditar em suas potencialidades e desenvolver suas ideias. Nesse nível, as atividades de repasses técnicos sobre o desenho do Mangá também facilitou na criação do personagem, estimulando alunos que não estavam abertos ao desenho, a produzirem seus personagens.

Quanto aos resultados do processo criativo, o grupo C (imagem 3) pertencente a esse nível, assim como a maior parte dos demais grupos, demonstrou uma melhor percepção social e criatividade em movimentar seu personagem em meio à comunidade. $\mathrm{O}$ grupo composto unicamente por meninas, trabalhou a problemática da mulher em meio à sociedade, criando personagens com roupas extravagantes, assim como maquiagem e cabelos bem elaborados.

Como resultado, ao sair do ambiente da escola e caminhar nas ruas da cidade, o grupo percebeu que o problema que trabalharam apenas por ouvir falar, realmente existia e foi visualizado a partir de atitudes da sociedade, que descriminou e condenou, em sua maioria, aquele grupo, pelas roupas que usavam e o modo que se portavam. Assim, fica clara a fala de que o Mangá pode ter diversas funções pedagógicas e pode ser pensado no ambiente de sala de aula para propor inúmeras situações e percepções com os alunos (LINSINGEN, 2007). Da mesma forma o Cosplay a partir de inspirações da performance artística, também possibilitou a saída destes alunos do ambiente de sala de aula, fazendo-os perceber melhor a diferença e a sociedade, ao conhecer e experimentarnovas realidades, resultando em novas experiências que darão forças à formação como indivíduos sociais.

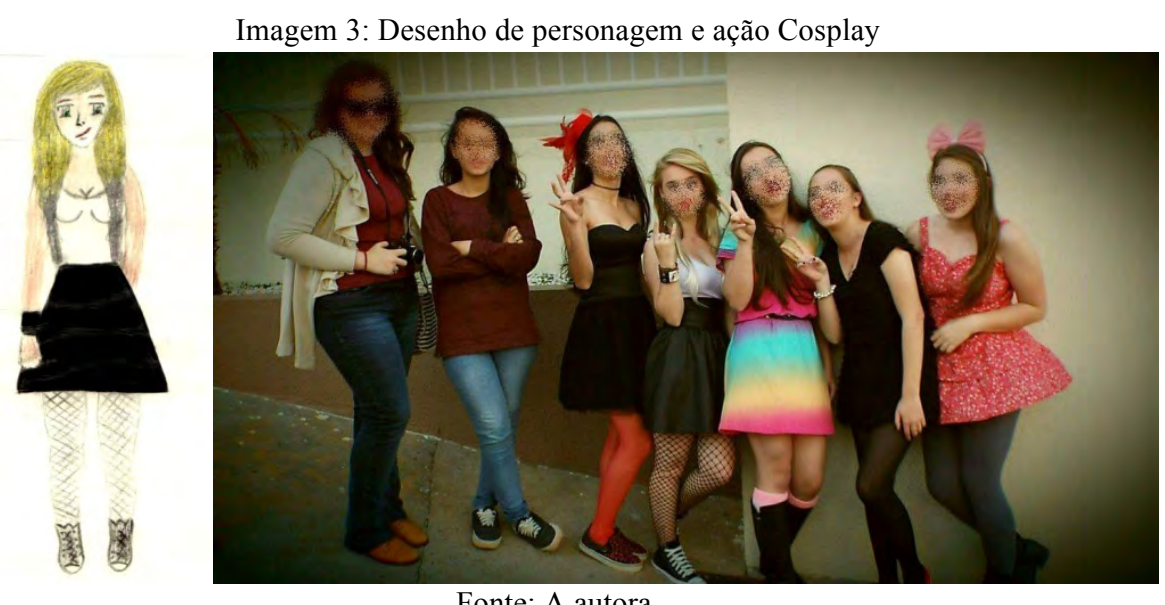

Fonte: A autora. 
Como início do segundo eixo deste relato, destaca-se aqui, o último nível, que não receberá um número de classificação e nem será referido como superior ou inferior aos demais, desconheceu completamente os termos, e apresentou algumas dificuldades em lembrá-los quando solicitado. Composto por associados envolvidos com o grupo de teatro da Associação de Deficientes Visuais do Oeste de Santa Catarina, a turma de 11 alunos estava distribuída entre pessoas cegas totais, e com baixa visão, nas idades de 7 a 50 anos.

Diferente dos outros níveis, foi a partir da experimentação em artes que os termos Mangá e Cosplay foram repassados como inéditos para o grupo de pessoas com deficiência visual. Apesar das diferentes idades presentes na turma, notou-se uma quase nula cultura visual em meio aos associados. Considerando aqui, a já citada fala de Vigotski (2003), que aborda o processo de formação do indivíduo na infância a partir de estímulos dos diversos sentidos. É possível pensar que o indivíduo com cegueira não se encontra em um nível inferior aos diferentes níveis de ensino, porém não pôde receber estímulos da visualidade, os quais compõem parte da formação desta pessoa. Com isso, "No ensino de um cego, deve-se substituir os vínculos de certos estímulos por outros, porém ao mesmo tempo todas as demais leis psicológicas e pedagógicas em que a educação se baseia continuam em vigor" (VIGOTSKI, 2003, p.259). Sendo assim, torna-se necessário pensar novas formas de ensinar, perceber e visualizar assuntos, de modo que por meio de outros estímulos essa pessoa possa acessar assuntos diversos de maneira diferente, mas qualificada para permitir a:

Incorporação do cego à experiência social das outras pessoas [...] devemos exigir que a experiência do cego possa ultrapassar os estreitos limites de seu defeito, para que ele possa se relacionar da forma mais vasta e direta com a experiência social da humanidade (VIGOTSKI, 2003, p.259).

As mesmas propostas lançadas para os outros níveis de ensino, também fizeram parte deste nível, porém devido à disparidade de idades, o ambiente de ensino não-formal e a deficiência visual dos alunos, novos meios foram pensados, de forma a estimular outros sentidos como o tato e a audição. A base das docências foi o diálogo, uma vez que os alunos estavam dispostos a ouvir e contar sobre suas dificuldades e medos perante as Artes Visuais e os conteúdos propostos. De modo a incentivar a aproximação dos associados com a arte Visual, falou-se sobre o texto de Ferraz e Fusari (1992), o qual descreve a importância do saber ver, que não se caracteriza pelo ato fisiológico da visão, mas que abrange experiências, ambientações, e está sujeito a uma educação perceptiva que instiga o percurso visual e os 
elementos selecionados. "O ato de ver ao ser aprimorado permite-nos observar melhor o mundo, o ambiente, a natureza. Um bom observador, investigando detalhes, encontrará particularidades que poderão enriquecê-lo.” (FERRAZ; FUSARI, 1992, p. 75). Com isso, falou-se sobre a importância de investigar situações, ambientes e objetos, por meio dos outros sentidos, conhecê-los e mentalizá-los de modo que a composição visual proposta pelo aluno com cegueira, esteja clara em sua mente, permitindo a ele expô-las de formas próximas a si próprio, porém capazes de comunicar ao outro.

Ao questioná-los sobre a prática do desenho, apenas uma das presentes alegou praticar e admirar a atividade, os demais mostraram repulsa e consideraram desnecessário para suas vidas. Entretanto, de modo a instigá-los, pensou-se na fala de Roig (2009), que via o desenho também como um planejamento, antes de alcançar produções finais. Com isto, foi proposta uma ação do desenhar diferenciada para estes alunos. Ao invés de usarem suportes comuns para o traçado, os associados deveriam utilizar a mente como suporte imaginário para traçar características e personalidades para o seu personagem, gerando assim, um desenho mental que seria exposto por meio da escrita para as demais pessoas. O grupo se interessou pela ideia, alegando-a mais próxima às suas realidades, questionado o porquê, de por vezes serem obrigados a produzir desenhos com folha e lápis, se ao fim, jamais saberão o que registraram ali.

Desta forma, a criação de personagem para performance não foi traçada como um Mangá, mas sim, com características imaginativas dos associados, como no caso do aluno $\mathrm{F}$ que descreveu sobre sua criação: "O nome desse personagem é Tia do Lanche. Ela é uma senhora de meia idade, com o rosto desgastado pelo tempo. É amável e paciente até o momento que a tiram do sério, que é quando ela se transforma em um monstro!Ela veste aquelas roupas de cozinha, um casaco azul e a touca que não pode faltar." Foi a partir desta percepção, acompanhada de descrições, de materiais adaptados e em poder criar um personagem mentalmente, que conceituar Mangá ficou mais próximo do entendimento dos associados, uma vez que perceberam que para criar uma história, seja ela qual for, é preciso planejar um personagem, e caracterizá-lo de formas específicas, para então encaixá-lo em uma história ou contexto.

Em contrapartida, a performance e Cosplay, apesar de não fazerem parte do entendimento dos associados, despertou interesses na turma, a qual os considerou mais concretos e possíveis de perceber. As mostras de performances, ao invés de serem feitas por áudio descrição de vídeos foram descrita a partir da atuação dos alunos, os quais conforme as 
narrações, realizaram as ações de artistas como Joseph Beuys e Berna Reale. Ao perceberem a ligação do Cosplay com um amor ao personagem e a performance como uma linguagem em artes, as diversas temáticas para produção do Cosplay performático abrangeram situações do cotidiano dos alunos, em uma defesa à inclusão e ao respeito perante a pessoa com deficiência visual. O aluno T (imagem5), desenvolveu sua ação performática no espaço da associação e nomeou a problemática de sua ação como: "Você não precisa ter pena de mim, quem pode me provar que enxergar é melhor do que não enxergar?”. Com isto, sentou-se, e com o auxílio de uma colega que indicava em seu ouvido quem era a pessoa que estaria passando, soltava altas gargalhadas e declarava sua pena pelas pessoas que podiam ver este mundo, afinal o mundo era tão cruel, qual seria a graça de ver?

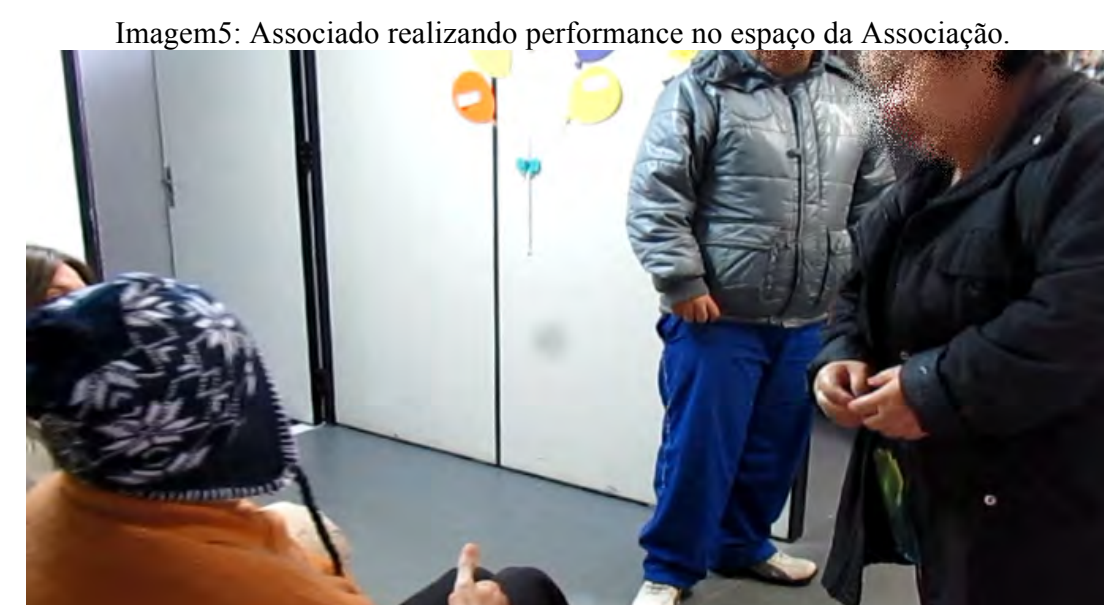

Fonte: A autora.

A partir do planejamento dessas ações, inúmeras reflexões sobre a pessoa com deficiência visual na sociedade surgiram e foram debatidas pelos associados que se mostraram preocupados e, por vezes, inconformados com situações de exclusão e falta de inserção social.

No nível um, dois e três, conforme Vigotski (2003), percebeu-se a evolução dos alunos em relação às temáticas e linguagens abordadas, conforme suas experimentações e vivências. Demarcando claramente uma escada que percorreu níveis de conhecimento e caracterizou o primeiro eixo desta pesquisa. Entretanto, ao pensar no último nível, que foi chamado assim apenas por ter sido a última ação de docência realizada, percebeu-se que não havia um nível de conhecimento a ser encaixado com a turma, que a evolução não era clara e que os estímulos, as experimentações e as vivências que até ali os levaram, não foram suficientes para os fazerem produzir pontos de vistas e saberes sobre as temáticas abordadas. Rumando, assim, para o segundo eixo, uma vez que foi por meio de aulas de artes, que os temas Mangá e Cosplay foram apresentados, como uma cultura popular que tem se expandido 
no Brasil, e deve também ser percebida e situada para pessoa com deficiência visual. Trazendo o ensino de artes para uma perspectiva que vai muito além de práticas ou repasses de conteúdos, mas que é capaz de instigar uma educação visual, social, cultural e crítica, cheia de propriedades intelectuais, fundamentais para a formação de indivíduos, independente da situação deste (BARBOSA, 2002).

\section{CONSIDERAÇÕES FINAIS}

A partir da cultura popular do Mangá e do Cosplay, que há quase um século tem se erguido em meio à juventude brasileira, relacionada com linguagens das Artes Visuais, percebeu-se que é possível trabalhar com temas da proximidade dos alunos e guiá-los para novos conhecimentos e processos em artes, assim como, por meio do contato do indivíduo com as artes, levá-lo a temas totalmente desconhecidos, e permiti-lo constatar novas culturas, assuntos e problemáticas que cercam a diversidade.

Do Mangá ao Cosplay: processos criativos e performáticos no ensino das Artes, objetivou inicialmente processos criativos que envolvessem o Mangá e o Cosplay na sala de aula, porém resultou em problemáticas e análises mais profundas que não se resumem aqui, as quais trouxeram aos educandos novos olhares perante a sociedade, a arte e a si próprios, gerando um rico material a ser pensado e pesquisado nos diferentes níveis de ensino, com os mais diversos indivíduos. Por fim, não foram concluídas e nem finalizadas as discussões acerca desta proposta no ensino de Artes, porém, durante esta etapa, percebeu-se que o ensino de Artes tem uma incrível potencialidade em envolver educandos de forma mais sensível, colaborando para a construção de indivíduos mais humanos e prontos para pensar em arte, inclusão e sociedade, e o Mangá e o Cosplay podem ser conteúdos que instiguem esse percurso na Educação Artística.

\section{REFERÊNCIAS}

ALVES, SÍLVIA REGINA FERRARI LUCAS. Investigação acerca da performance e seus aspectos relacionados a preparação do performer. 2010. 41f. Monografia (Licenciatura em Teatro) - Universidade Federal do Rio Grande do Sul, Rio Grande do Sul, 2010.

AVARI, Frederico Cirota; ROSA, Ednilton José Santa. Cosplayers sob uma perspectiva crítica.VII Jornada De Iniciação Científica. Universidade Presbiteriana Mackenzie. 2011. 
ASHCRAFT, Brian; PLUKET, Luke. Cosplay World.Estados Unidos: Prestel, 2014.

BARBOSA, Ana Mae Tavares Bastos. A imagem no ensino da arte: anos oitenta e novos tempos. 5. ed. São Paulo: Perspectiva, 2002. 13410

. Tópicos utópicos. Belo Horizonte: Com Arte, 1998.

CARLOS,GiovanaSantana.Mangá: O Fenômeno Comunicacional No Brasil.In: X Intercom Sul, 2009, Blumenau. Intercom Sul, 2009.

COELHO JUNIOR, Leconte De Lisle. Um estudo sobre a violência em duas histórias gráficas. Revista Brasileira de Crescimento e Desenvolvimento Humano, Faculdade de Saúde Pública/USP, v. 15, n.1, p. 55-68, 2005.

Cosplayers no Brasil: O Surgimento de Uma Nova Identidade Social na Cultura de Massas.Universidade Federal do Espirito Santo, UFES.2008.

COHEN, Renato. Performance como linguagem: criação de um tempo-espaço de experimentação. 2. Ed. São Paulo: Editora Perspectiva, 2002.

DERDYK, Edith. Formas de pensar o desenho: desenvolvimento do grafismo infantil. 2. ed. São Paulo: Scipione, 1994. 239 p.

O desenho da figura humana. 2. Ed. São Paulo: Scipione, 2003. 174 p.

FERRAZ, Maria Heloísa C. de T.; FUSARI,Maria F. de Rezende E.Arte na Educação Escolar. São Paulo: Editora Cortez, 1992.

Metodologia do Ensino de Arte.São Paulo: Editora Cortez, 1993.

GRAVETT, Paul. Mangá: como o Japão reinventou os quadrinhos. São Paulo: Conrad, 2006.

LINSIGEIN, Luana von. Mangás e sua utilização pedagógica no ensino de ciências sob a perspectiva Cts. Ciência \& Ensino (Online), V. 1, P. 1-9, 2007. São Paulo: Campinas, set. 2012.

LUYTEN, Sonia Bibe. Mangá: o poder dos quadrinhos japoneses. São Paulo: Hedra, 2011.

MIRANDA, Simão. Metodologia científica os caminhos do saber. 2007. Disponível em: $<$ http://blog.fimes.edu.br/gildomar/files/2011/08/7299971-Pesquisa-e-Metodo.pdf $>$. Acesso em: 04/04/2015.

MOLÍNE, Alfons. O grande livro dos Mangás. São Paulo: Editora JBC, 2004

NUNES, Mônica Rebecca Ferrari (org.). Cena Cosplay:comunicação, consumo, memória nas culturas juvenis. Porto Alegre: Sulina, 2015. 
PEREIRA, DANIELA ALVES. Joseph Beuys: uma investigação sobre modos de ação. Revista aSPAs, v. 4, p. 92-101, 2014.

PEREIRA, Katia Helena. Como usar Artes Visuais na sala de aula. São Paulo: Editora Contexto, 2007.

PIANOWSKI, Fabiane. O corpo como arte: günterbrus e o acionismo vienense.RevistaObservaciones Filosóficas, v. 5, p. 2, 2007.

ROIG, Gabriel Martín. Fundamentos do desenho artístico. 1. ed. São Paulo: Martins Fontes, 2009. 255 p.

SANTO, Janaina De Paula Do Espírito. Mangás e cultura histórica: entre o escolar e o cotidiano. Anais do XXI EncontroEstadual de História - ANPUH- 2012.

SANTOS, José Mario Peixoto. Breve histórico da "performance art" no Brasil e no mundo.Revista Ohun, v. 4, p. 1, 2008.

VIGOTSKI, Liev Semionovich. Psicologia pedagógica: edição comentada. Porto Alegre: Artmed, 2003.

.Imaginação e criação na infância: ensaio psicológico: livro para professores. 1 . ed. São Paulo: Ática, 2009. 